\title{
Second Order Coherence: A new way of looking at incoherence in texts
}

\author{
Ib Ulbaek \\ University of Copenhagen, Denmark
}

\begin{abstract}
By using van Dijk's concept of coherence and bringing it together with my Principle of meaning iconicity, we have a new way of looking at incoherence in texts. The principle says that closely related information is meaningfully related on a pragmatic level, an instruction to the reader to relate the information to each other. It is demonstrated by textual analysis that the concept of coherence can be used analytically by dividing it into first and second order coherence. First order coherence is the usual concept of coherence: sentences are connected by cohesive links and related by causality, time etc. Second order coherence is a way of organizing text by using incoherence as a way of organizing text into chunks of coherent parts. It is shown how readers can detect these structures in the text by detecting the incoherence even without the layout of the text to signal structure (e.g. indention of paragraphs).
\end{abstract}

Keywords: text linguistics, coherence, text analysis, pragmatics

\section{Introduction}

The concept of coherence is a blunt instrument when it comes to describing and analyzing texts. In the tradition from Beugrande and Dressler (1981) it vaguely means that the text is a whole when its elements are connected. Van Dijk (1977) analyzed coherence as referential sameness, an analysis later considered as simpleminded and shot down by various counterexamples. Most famous in the "Calderon was a great writer. We will have guests for dinner". But in a context where the guests are scholars of Calderon the text makes sense, and therefore it is meaningful without anaphoric relations between sentences. But as soon as you put this information into the text, as in "Calderon was a great writer. We will have guests for dinner. They all love him", the text is exactly coherent due to the anaphoric relation - the information bridges between the first and second sentence. I therefore suggest revitalizing the van Dijk concept of coherence. By bringing it together with my Principle of meaning iconicity (Ulbæk 2005), we have a new way of looking at incoherence in texts. The principle says that closely related information is meaningfully related on a pragmatic level, an instruction to the 
reader to relate the information to each other. It is demonstrated by textual analysis that the concept of coherence can be used analytically by dividing it into first and second order coherence. First order coherence is the usual concept of coherence: sentences are connected by cohesive links and related by causality, time etc. Second order coherence is a way of organizing text by using incoherence as a way of organizing text into chunks of coherent parts. It is shown how readers can detect these structures in the text by detecting the incoherence even without the layout of the text to signal structure (e.g. indention of paragraphs).

\section{The importance of the concept of coherence}

As has been known at least from the time of Beugrande and Dressler's significant book, Introduction to text linguistics (1981), the concept of coherence is a sine qua none for understanding the concept of text. In a sense it is the backbone of text linguistics. One of the seven defining characteristics of texts is that it is coherent.

"A text "makes sense" because there is a CONTINUITY OF SENSES among the knowledge activated by the expressions of the text (cf. Hörmann 1976). A "senseless" or "non-sensical" text is one in which text receivers can discover no such continuity, usually because there is a serious mismatch between the configuration of concepts and relations expressed and the receivers' prior knowledge of the world. We would define this continuity of senses as the foundations of COHERENCE, being the mutual access and relevance within a configuration of CONCEPTS and RELATIONS.'

(Beaugrande and Dressler 1981: 84)

So, coherence is when there is "continuity" in the text, incoherence is when there is discontinuity. The coherence of the text makes it possible for the reader to build one mental model of the topic(s) of the text, whereas incoherence may split topics into different and unrelated mental models or in the worst case into no mental model at all (on mental models, Togeby 1993, Johnson-Laird 1983). ${ }^{1}$ So, incoherence is seen as a deficiency of the text, which of course can be true and make texts unreadable and unable to fulfill any communicative intention at all. But total incoherence is rare, more often there will be local incoherence, which can be repaired or circumvented still leaving most of the text intact. Later, I will present a different kind of view of incoherence in texts, which serves a function in organizing the text and which have been overlooked, maybe due to the expectation that incoherence cannot be an ordinary part of texts.

\section{Development of the concept of coherence}

As is well known, the concept of continuity is not enough to explain coherence in wellformed texts. Teun van Dijk showed that you can have continuity in texts which, so to speak, drift away from an overall topic of the text, as in (1).

\footnotetext{
1 I use "reader" as the receiver of text due to my definition of text as primarily a form of language use carried by writing. Text is monolog, planned and of limited size such that the end is anticipated from the beginning, such that all goals presented from the start are fulfilled when the text ends (cf. Ulbaek, 2005).
} 
(1) 'John was ill, so he called the doctor. But the doctor could not come, because his wife wanted to go to the theater with him. They were playing Othello which she thought they could not miss because Shakespeare was one of the few dramatic writers who...'

(van Dijk 1980: 40)

What we see in this nicely constructed example is local coherence. There are anaphoric connections between each consecutive proposition, and each consecutive sentence gives a reason for the previous proposition. The continuity is present, but a main topic is missing, the first proposition raises a question in the readers mind about John's disease which is fading away in the way the text is digressing. The text is lacking global coherence.

For the purpose of understanding the relation of local and global coherence in texts van Dijk developed the concept of macrostructure. By having four rules of reduction (three, actually, the zero rule did not compress the text) used recursively under the guidance of dominance and subordination of information in paragraphs, he was able to show that the text could be reduced to ever smaller texts still in coordination with the original one being an ever shorter abstract until one proposition is left: The macroproposition showing the text to be one and global coherent and expressing the main topic of the text (cf. van Dijk 1980, Ulbaek 2005).

My own theory of pipelines is giving a dynamic account of coherence between paragraphs in texts (Ulbaek 2001, 2005). In short, I have formulated a principle of meaning iconicity which claims,, ceteris paribus, that the closer two meaning components are, the closer they are physically related. As a reader you would expect two meaning entities to be relevant for each other, if placed together. It is in a sense both trivial and weak; trivial because we expect the phonemes of a word to be together and not distributed among the other words (anagrams of course an exception), a phrase to be grouped together, a sentence to border on other sentences etc. The principle is weak because it does not confer or predict the kind of structure the linguistic entity has. Still, it is important. Paragraphs are grouped likewise both within themselves and among other paragraphs. Internally, the paragraph carries a subtopic within the text's superordinate topic, the different paragraphs of the text carrying the different topics that is required to fulfill the purpose of the text, having the depth of intention as required by purpose and genre (for depth of intention, see Togeby 1993, borrowing the term from Arne Naess (1966). The consequence of the principle of meaning iconicity for the ordering of paragraphs is obvious: They will be ordered in such a way that they are related in a meaningful way. And the meaningful relation is expressed through pipelines: a proposition in a subsequent paragraph is connected to a proposition in the previous paragraph creating a pipeline of information between the two paragraphs. The second paragraph is connected to the first and in turn connects to the next and so forth through the text making it a connected whole with a rather flat structure. An example of this will be given later (but see for further elaboration Ulbaek 2001, 2005).

All this is of course important steps in explaining coherence in texts, but notice that lack of continuity, connectedness and structuring is only seen as leading to incoherence, breakdown of structure, making the text break down. In the following, I will investigate whether this is actually true. Could incoherence in text serve a function? In my opinion incoherence can be benign as well as malignant, to use a medical metaphor. 
In the following, I will develop the concept of second order coherence, which depends on certain forms of incoherence in texts and which shows the function of incoherence.

\section{First order coherence}

For my theory I need a way of characterizing ordinary coherence. I will revive the theory of coherence which was suggested by van Dijk (1977), which states that coherence depends on sameness of referents or discourse referents across consecutive propositions, as in example 2.

(2) I saw a funny Roll Royce yesterday. The car was painted flower power-like.

In (2) there is a sameness of referent in both sentences, a certain type of car. The car is anaphorically related to Rolls Royce as this expression can or will establish in the reader's mind a discourse referent, and the car is identified with this discourse referent due to automatic inferences guided by different principles (e.g. the principle of meaning iconicity; the drive to minimize the number of discourse referents in a text (Ulbaek 2005); the form of the expression itself (determined NP)). The negative side of this is then, that if there is no reference to the same discourse referent(s), then there will be incoherence, as in van Dijk's famous Calderon-example (3).

(3) We will have guests for lunch. Calderon was a great Spanish writer.

None of the first propositions discourse entities (we, guests, lunch) is taken up in the second proposition. Instead Calderon is predicated as a great Spanish writer.

This view of coherence as continuation of referents through the text has been questioned and in the example shown above to fall short of giving the correct analysis. Livia Polanyi (1995) used the above example to show that given the right kind of context the sequence in (3) makes full sense. Given that the guests are all fans of Calderon, the second proposition makes sense as their high estimation of him. Does it mean that the sequence in (2) was coherent after all? Yes and no. No, as it stands it isn't, but given the extra information, can be regarded as coherent - in that context. But what happens when you put the contextually given information about the guest into the sequence? Consider (4).

(4) We will have guests for lunch. They are all fans of Calderon. Calderon was a great Spanish writer

We can see that the incorporated information does bridge the information in first proposition to the (now) third sentence. When the information that was assumed known in the context is placed in the sequence, it turns the sequence into a coherent whole due to the factors claimed necessary by van Dijk (1977).

So, in the following, I will be inspired by van Dijk's definition of coherence and name it first order coherence (or 1. order coherence). I use it as a method of tracing sequences of coherence through a text and detecting when coherence ends by breaking the chain of discourse referents. This incoherence can give rise to second order coherence (or 2. order coherence). 
The point of having the concept of first order coherence seen in this way is that the concept of coherence (and, mutatis mutandis, incoherence) is rather clear cut: Whenever the relation between discourse referents can be sustained, there will be coherence, whenever the relation cannot be established (e.g. by inference) by the reader, he will experience incoherence and the text as a unity will break down.

Here is an example of first order coherence (5).

(5) 'As argued above, the following articles enjoy considerable conceptual and theoretical overlap. All deal with a mixture of theoretical and analytical questions, and these are often deeply interdisciplinary.'

(Auken et al. 2015: xx)

As can be seen, there is an anaphoric relation between the two bold expressions and likewise between the two in italic thus relating the three propositions expressed by the sentences. The text is coherent.

Incoherence is then when no relation can be made, as in (6).

(6) Time is now $11 \mathrm{am}$, and I am John Doe. This is PopFM.

In (6), which mimes the announcing of a radio program, there is no relation between the proposition as there are no relations between the discourse referents in them. It does not constitute a text and do not pretend to do so. It is a list of unrelated information all of which is relevant on its own but not to each other.

A related phenomenon happens when the speaker makes flow in the announcement by relating predicates between propositions, as in (7).

(7) The weather will be warm tomorrow. And our next guest is hot too.

I term this kind of pretending coherence as pseudocoherence, as it relates two phenomena which have nothing in common except that the same kind of predicate can be applied to it (Ulbaek, 2005).

Ordinary text, most texts in fact, will have these broken bonds between discourse referents. Does it mean that ordinary texts are incoherent and a fortiori not textual unities, after all? That will make this concept of coherence too severe and be a contradiction in terms. This is where second order coherence comes in.

\section{Second order coherence}

The point of the concept of second order coherence is that it restores coherence, not by establishing relations between discourse referents, but by establishing structure and order in the text.

Text writing and reading is guided by the principle of meaning iconicity (Ulbaek 2005). The principle states that the closer two text units are physically, the more related they are. It's an ordering principle. Two adjacent sentences or propositions can, by this principle, be expected to be relevant for each other. That is what happens in the Calderon-example above. The list in (6) should give rise to the same expectation, but seldom do, as we are used to the 
format. But one of the Danish newspapers on the internet has begun to brief its readers, so it is a new format here. The briefing is introduced by a similar list as in (6), but as you mistake it as an ordinary text, it activates the principle of meaning iconicity, see (8).

(8) 'Kvinde fra Kazakhstan slår hul til 47 mio. dokumenter. Slut for toppolitiker: I fængsel i halvandet år. Columbine High-massemorders mor taler ud.'

(Jyllands Posten: Briefing 02-15-2016)

[Woman from Kazakhstan beats hole to 47 million documents. End of politician: In jail for eighteen months. The mother of Columbine High mass murderer speaks out.]

At first in reading this you feel that you are led down a garden path/blind alley, as you try to make the second sentence relevant to the first, trying to figure out what role the jailing of the politician has in the mysterious first proposition about this woman getting access to the huge amount of documents. I usually detect the incoherence quickly by searching for genre information, finding the "briefing" located above in a pale font, thereby separating the information in, here, three independent propositions. Turning text construction into list construction. Actually, this is the same kind of inference as is going on in establishing second order coherence, making structure in text, but now the result is not a list but a text.

Second order coherence is invoked when one is:

a) reading a text one sentence at a time;

b) expecting the sentences to be relevant to each other (the principle of iconicity);

c) trying to establish first order coherence but fails;

d) detecting that the text is incoherent;

e) inferring that the incoherence is there for a reason;

f) establishing what that reason is by imposing structure on the text;

(g) identifying what kind of structure - e.g. the production form.)

Instead of seeing this incoherence as a malignant feature of the text, it will in most cases work as a signal to the reader to infer second order coherence. The text does not break down but is given a structure (anticipated, of course, by the writer).

The process resembles the Gricean procedure for finding implicatures (Grice 1989). So, by the principle of cooperation which here is supplemented or crystalized by the principle of iconicity, the reader is expecting the consecutive sentences to be relevant to each other sequentially. They will be so if first order coherence can be established, but it will not be relevant, if there is first order incoherence. Still expecting the cooperative principle to be obeyed by the writer, the reader will look for - not implicature, - but second order coherence (see Table 1).

Table 1: Comparison between implicature and second order coherence

\begin{tabular}{cc}
\hline Grice & Second order coherence \\
\hline Inference from what is said & Inference from first order incoherence \\
\hline To what is meant: implicature & To second order coherence \\
\hline
\end{tabular}

So, by detecting first order incoherence the reader imposes structure on the text, which saves coherence, not first order, but second order. The reader divides the text into chunks of 
information within which first order coherence obtains. Between the structures, then, there is second order coherence. First part of the text has a theme, second part of the text has another theme. Second order coherence connects the two parts into a coherent whole, such that the text can develop a certain topic in the depth to which the text is designed to treat its topic. Second order coherence is also assigning functions to the different parts of the texts.

When commencing reading a text, the reader will naturally expect the first part to be a presentation form of the type orientation (Chafe 1994). But some texts, e.g. journalistic interviews, start with a teaser, the journalist himself walking up a street to go to a bar. The orientation then comes later and so to speak pulls back the guess "orientation" from the first part and reassigns it e.g. "description".

If the text is to be a successful coherent whole, there have to be parts of the text where first order coherence obtains, and if first order does not obtain, it marks the borders of these parts. If it is possible to detect second order coherence between the parts the text as a whole has a structure - and is coherent. This structure can then be seen as a macrostructure (van Dijk 1980), the parts having a macroproposition. The macropropositions of the parts taken together form a condensed abstract of the text, itself being able to be further reduced to a single macroproposition expressing the overall topic of the text, showing it to be one coherent whole. But as suggested underneath the macrostructure the text has to be given the structure on which the reduction rules can be applied. This is the work of second order coherence.

This theory of first and second order coherence shows that coherence is not an either-orconcept. Coherence comes in degrees: parts of the text are more coherent than other parts.

\section{Text Analysis}

In this section, I will by way of text analysis show how the concepts of first and second order coherence work together to generate structure in the text.

The text is chosen at random from the Internet: Joyce Wadler: The Sex Toys in the Attic, (New York Times, November 9, 2013). ${ }^{2}$ I will analyze the first part of the text (see below).

'I've been thinking about an extremely beautiful sex toy an old boyfriend got me - I think it is on my mind because he is having heart surgery this week. This is how it is at a certain age; when you hear about an old boyfriend it's not because he got married or got a great job, it is because they're threading tubes into his chest and doing an ablation on his heart.

This toy, which was silver and shaped like a stylized banana, was so complicated I never used it. Also you had to charge it for a few hours. It wasn't one of those things that charged with a discreet little light either; it blasted O-shaped strobe signals across a dark-ened room that could have been used to direct incoming flights at a small airport, ideally one catering to businessmen whose wives had lost interest in sex years ago. Well, that's what they all say, isn't it?'

(Wadler 2013)

2 http://www.nytimes.com/2013/11/10/booming/the-sex-toys-in-the-attic.html?src=me\&ref=general

3 In my Danish paper on second order coherence (Ulbaek 2013a) I have used the same procedure: to pick texts at random to enhance the validity of the theory. 
Due to the principle of iconicity of meaning we as readers will expect the sentences to be sequentially relevant for each other. And the same goes for the two paragraphs. This is the weak ordering imposed by the principle: The information is not presented at random. But of course it is not enough to have the expectation, the text has to fulfill the promise by being coherent.

'I've been thinking about an extremely beautiful sex toy an old boyfriend got me <and what about the sex toy?> - I think it is on my mind because he is having heart surgery this week <and what about his heart surgery? >. This is how it is at a certain age; when you hear about an old boyfriend it's not because he got married or got a great job, it is because they're threading tubes into his chest and doing an ablation on his heart.'

In the first paragraph there are three chains of anaphors:

a) The I of the author: I've - I - you (including the author).

b) the sex toy: an extremely beautiful sex toy - it

c) the boyfriend: an old boyfriend - he - an old boyfriend - his chest

The information structure (Lambrecht 1994) of the first sentence has the sex toy as topic, and is commented on in the second sentence which changes the topic to the boyfriend in the third sentence and his heart surgery, which the rest of the paragraph is commenting on in a general fashion. So, the whole first paragraph is first order coherent. To complete the anaphor-analysis, the they-pronoun looks unidentified as there is neither an anaphoric or cataphoric relation to a discourse referent. But the concept "heart surgery" opens a frame of surgeons operating patients. So the inference is easy for the reader: to identify the pronoun with the implicit discourse entities (surgeons).

Next, I will analyze the last sentence complex in the first paragraph and the first sentence of the second paragraph.

'This is how it is at a certain age; when you hear about an old boyfriend it's not because he got married or got a great job, it is because they're threading tubes into his chest and doing an ablation on his heart.

$<$ incoherence between paragraphs>

This toy, which was silver and shaped like a stylized banana, was so complicated I never used it.'

Seen separately there is no connection between the two, which means that the text is incoherent at this point. But as already mentioned the text does not break down because the reader expects the text to be coherent (by the principle of meaning iconicity), and it is: It is second order coherent. The incoherence is a signal of a change of subject, so second order coherence is making a structure of the text. The first paragraph is primarily about the boyfriend and his heart surgery, a sign of being old. The second paragraph is about the sex toy, a topic for the rest of the article.

The first paragraph looks at first as if it is about the sex toy, but it changes subject to the old man and his heart surgery. When the second paragraph returns to the topic of the sex toy - and it turns out the man almost never is commented on again, it actually not only structures the text, but also allows the reader to infer the presentation form of the first paragraph: It is a digression as a part of an orientation about the topic (on orientation, see Chafe 1994). 
The second paragraph has a very strict first order coherence structure, as the reader can assure himself. The topic is the awkwardness of the sex toy, the way it lights up the room when being charged. So the presentation form is description.

I have pointed out that there is incoherence between first and second paragraph when you proceed sequentially through the text reading one sentence at a time. But clearly the two paragraphs are not unrelated. Coherence is not either-or; parts of texts are more coherent than others. As stated above, the principle of iconicity of meaning also works for paragraphs. The two paragraphs are next to each other because they are related. And the relation can be traced by what I call a pipeline structure (Ulbaek 2001). The pipeline metaphor is used because of some similarities to a real oil pipeline. The pipeline is connecting a source of information and a goal of information. The unit of information is the proposition. The pipeline is connecting a proposition in the first paragraph and a proposition in the next, as can be seen in the sex toy text. The pipeline is connecting the two italicized propositions:

'I've been thinking about an extremely beautiful sex toy an old boyfriend got me - I think it is on my mind because he is having heart surgery this week. This is how it is at a certain age; when you hear about an old boyfriend it's not because he got married or got a great job, it is because they're threading tubes into his chest and doing an ablation on his heart.

This toy, which was silver and shaped like a stylized banana, was so complicated I never used it. Also you had to charge it for a few hours. It wasn't one of those things that charged with a discreet little light either; it blasted O-shaped strobe signals across a dark-ened room that could have been used to direct incoming flights at a small airport, ideally one catering to businessmen whose wives had lost interest in sex years ago. Well, that's what they all say, isn't it?'

(Wadler, op. cit.)

Due to the way the paragraphs can be organized, the pipeline structure will not be simply connecting the last proposition in the first paragraph to the first proposition in next paragraph - or: it doesn't have to do so. That it doesn't happen in the chosen example here is because of the digressive content of the first paragraph. The thoughts of the old boyfriend would not be a digression if the author continued writing about him further on. He is mentioned, though, in the fourth paragraph: "But now, with the old beau's surgery looming, the toy - rather its disposal - was on my mind" (Wadler, op. cit.).

So there is a pipeline between the first paragraph and the fourth, relating information about the boyfriend in both paragraphs, but as can be seen, he is not the topic of the fourth paragraph. The topic stays on the sex toy. And, actually, the mentioning of him again isn't necessary to understand the problem of getting rid of the toy. His function is primarily being the giver of the toy and being old and ill (two themes that runs through the column without bringing him up again).

This textual analysis cannot be more than a demonstration of the way the theory of second order coherence is considered to be a tool for analysis of the way the text is structured.

\section{Detecting structure in a text - an experiment}

As has been shown above, the indentation marking paragraphs are a way of signaling second order coherence, a way of imposing visual structure on the total set of sentences making up a 
text. Guides to better writing often suggest just that: Whenever you start on a new subtopic make a new paragraph. But there is also more loose advice: Divide your text into short paragraphs to make it visually attractive. Text written for the Internet will often have this kind of very short paragraphs. The last way of dividing the text will of course not respect the structure given by the text itself, making paragraphs somewhat arbitrary. This arbitrariness can also be seen in untrained (and even in trained or professional) writers. Still, it seems reasonable that paragraphs primarily have the function of marking change of subject within the text.

So, where is the paragraph marking of the text? I have tested that question using my Danish students at The University of Copenhagen and students from two classes from a high school in a suburb of Copenhagen. The experiment is straightforward. You take any text having paragraphs that are indented, delete the indentation to make it unstructured. The subjects are not briefed on the purpose of the experiment, but they are asked to mark in the text with a pencil where they would divide it into paragraphs. They are told that there are no correct answers that they should try to figure out. They use 5 to 10 minutes to complete the experiment.

The text used is an editorial of a Danish newspaper, Politiken, the Internet version. ${ }^{4}$ The subject of the editorial is the near bankruptcy of the Scandinavian Airline System (SAS) calling for the politicians to take action to secure the company in the future.

The text consists of 18 sentences which are indented into 10 paragraphs. Here the first four are shown:

1. Ofte er det først, når man er ved at miste noget, at man erindrer, hvor meget det egentlig betyder.

2. Det har vi netop oplevet med luftselskabet SAS, der i går blev reddet på konkursens rand. 3. Der er al mulig grund til at udtrykke respekt for de medarbejdere, der nu har accepteret lavere løn og længere arbejdstid for at redde selskabet.

4. Nogle vil ekstrapolere SAS' situation til hele det danske arbejdsmarked, hvor Venstre har sat kollektiv lønnedgang på dagsordenen som svar på den økonomiske krise. 5. Men intet kunne være mere forkert. 6 . SAS har været i en helt ekstraordinær situation, og med-arbejderne har accepteret en ekstraordinær løsning.

7. Dermed har de ikke alene reddet deres egne arbejdspladser, men også en afgørende del af Danmarks infrastruktur og et stykke skandinavisk erhvervshistorie. 8. Det havde været en katastrofe for både København og Danmark, hvis flyselskab var faldet sammen efter års dårlig ledelse med skiftende strategier.

The Danish text is here translated into English:

1. Often it is only when you are losing something that one recalls how much it really means.

2. We have just experienced this with the airline company, SAS, which yesterday was rescued on the verge of bankruptcy. 3. There is every reason to express respect for the employees who have now accepted lower wages and longer hours to save the company.

${ }_{4} \mathrm{http}: / /$ politiken.dk/debat/ledere/ECE1818176/sas-er-noeglen-til-globalisering/ (since the experiment, the editorial has been locked, giving only access to the first part of it). 
4. Some will extrapolate the SAS' situation to the entire Danish labor market where the Liberals have put collective wage cuts on the agenda in response to the economic crisis. 5. But nothing could be more wrong. 6. The SAS has been in an extraordinary situation, and employees have accepted an extraordinary solution.

7. Thus, they not only saved their own jobs, but also a crucial part of Denmark's infrastructure and some Scandinavian business history. 8. It would have been a disaster for both Copenhagen and Denmark, whose airline company had collapsed after years of mismanagement with its erratic course. ${ }^{5}$

The experimental text is given to the subject without indentation as shown here:

1. Often it is only when you are losing something that one recalls how much it really means. 2 . We have just experienced with airline company, SAS, which yesterday was rescued on the verge of bankruptcy. 3 . There is every reason to express respect for the employees who have now accepted lower wages and longer hours to save the company. 4 . Some will extrapolate the SAS' situation to the entire Danish labor market where the Liberals have put collective wage cuts on the agenda in response to the economic crisis. 5 . But nothing could be more wrong. 6. The SAS has been in an extraordinary situation, and employees have accepted an extraordinary solution. 7. Thus, they not only saved their own jobs, but also a crucial part of Denmark's infrastructure and some Scandinavian business history. 8. It would have been a disaster for both Copenhagen and Denmark, whose airline company had collapsed after years of mismanagement with its erratic course.

\section{Results}

I tested university students and high school students, here $\mathrm{C} 1$ and $\mathrm{C} 2$, and I present the results individually for each class, due to their differences in age and gender distribution. I compare the results with the original (called $\mathrm{O}$ in Table 1) and my analysis (called $\mathrm{A}$ in Table 1) (original presented in Ulbaek, 2013b).

My own class (C1) in Danish language was 15 women and 1 man, average age 21.5 years. The two high school classes (C2) were 24 men and 15 women, average age 17.7 years.

What is represented as results in Table 1 is where each class as a whole would collectively divide the text into paragraphs. So, the paragraphs are placed where a majority of the subjects has marked for paragraphs in the text. The original paragraphs from the editorial have just been copied and my analysis is finding second order coherence.

Table 2

\begin{tabular}{|c|c|c|c|c|c|c|c|c|c|c|c|c|c|c|c|c|c|}
\hline Paragraph & 2 & 3 & 4 & 5 & 6 & 7 & 8 & 9 & 10 & 11 & 12 & 13 & 14 & 15 & 16 & 17 & 18 \\
\hline $\mathrm{C} 1$ & & $\mathrm{x}$ & $\mathrm{x}$ & & & & & $\mathrm{x}$ & & $\mathrm{x}$ & & $\mathrm{x}$ & & & & $\mathrm{x}$ & \\
\hline $\mathrm{C} 2$ & & & & & & & $\mathrm{x}$ & & & $\mathrm{x}$ & & & & & & $\mathrm{x}$ & \\
\hline $\mathrm{O}$ & $\mathrm{x}$ & & $\mathrm{x}$ & & & $\mathrm{x}$ & & $\mathrm{x}$ & & $\mathrm{x}$ & & $\mathrm{x}$ & $\mathrm{x}$ & $\mathrm{x}$ & & $\mathrm{x}$ & $\mathrm{x}$ \\
\hline A & & & $\mathrm{x}$ & & & & $\mathrm{x}$ & & & $\mathrm{x}$ & & $\mathrm{x}$ & & & & $\mathrm{x}$ & \\
\hline
\end{tabular}

As seen from the table, different results can be extracted as listed below.

a) None of the four groups have come up with identical results.

b) Two paragraphs are very robust as all four groups mark them: between sentence 10 and 11 , between sentence 16 and 17 .

5 The numbering was put into the text given to the subjects for ease of calculating the result; it wasn't, of course, part of the original editorial. 
c) Four places for not placing a paragraph are very robust in the same vein: $(4-5 ; 5-6 ; 11-$ 12 ; $15-16)$.

d) Two paragraphs are robust as three out of four mark them: $(3-4 ; 12-13)$.

e) Five places for not placing a paragraph are robust as three out of four do not mark them: $(1-2 ; 6-7 ; 13-14 ; 14-15)$.

f) O has most paragraphs not marked by the other three groups; C2 and A have least (none).

g) O has most paragraphs (10), C2 least (3). The average number of paragraphs are $6(\mathrm{C} 1$ is the average group).

h) If all four groups are pooled together to structure the text, it would consist of four paragraphs: $(3-4 ; 10-11 ; 12-13 ; 16-17)$.

i) $\mathrm{C} 1$ has 4 out of its 6 paragraphs among the very robust and robust paragraphs; $\mathrm{C} 2$ has 2 out of its 3 paragraphs among the same; $\mathrm{O}$ has 4 out of 10 and $\mathrm{A}$ has 4 out of 5 .

The results point to the non-arbitrary nature of paragraphs in the text. The overall organization of the text contains enough information for a skilled (and semi-skilled: the high school students) reader to detect the boundaries, of which the theory of second order coherence gives an account. And we see that the paragraph marking of the original text is not derived from the structure of the content of the text. The use of many and short paragraphs is guided by the convention of the Internet, making the text easy to read online on a computer screen.

Let me end this section of the article by looking at one of the two very robust paragraphs, the one between sentence 10 and 11 .

10. If the long-term threat is to be avoided, it requires a political response and reconsidera-tion of all the Scandinavian Governments on how we ensure our mutual airline company a future. 11. At yesterday's press conference SAS Chairman of the Board showed again that he is not the right person to head the company, as he outlined a strategy to prepare for a sale of the company.

In sentence 10, the topic is a call to the politicians to ensure a future for the airline company. In sentence 11, the topic changes to the role of the airline company's Chairman of the Board. In a sense the first order coherence breaks down because the change is big: from a political statement from the editor to an assessment of the strategy of the company. Therefore second order coherence gives reason to mark a new paragraph as seen in the students' reply, in the editorial itself and in my analysis. Still, the two propositions are not unconnected. There is room for an implicit relation connecting 10) and 11): To ensure the future of the SAS the Chairman of the Board should step back. Coherence and incoherence are fuzzy concepts and not a question of one or the other.

\section{Conclusion}

The aim of this paper has been to present a new theory of coherence within text linguistics. It takes a look at the concept of coherence and develops a theory that makes it useful as a tool for analysis of structure in texts. It does so by having a robust theory of coherence inspired 
from van Dijk (1977), calling it first order coherence. By applying the first order coherenceconcept on texts, it can be used to detect incoherence in texts. It is shown that this incoherence is (or can be) a part of the normal functioning of texts. It is a structuring device, dividing the overall topic of the text into subtopics, normally signaled by dividing the text into paragraphs. The procedure for detecting second order coherence resembles the Gricean procedure for detecting implicature, except that it doesn't find implicit meaning but implicit structure. To show its usefulness as a theory of coherence, analysis on part of a column is undertaken. Further, an experiment using a text without indentation shows that students are competent in detecting the structuring of the text.

\section{References}

Auken, S., P. Schantz Lauridsen and A. Juhl Rasmussen (eds.). 2015. Genre and...: Copenhagen Studies in Genre 2, Vol. 2 1. Valby: Ekbatana.

Beugrande, R.-A. and W. Dressler. 1981. Introduction to Text Linguistics. London: Longman.

Chafe, W. 1994. Discourse, Consciousness, and Time. The Flow and Displacement of Conscious Experience in Speaking and Writing. Chicago: The University of Chicago Press.

Dijk, T. van. 1977. Text and Context. London: Longman.

Dijk, T. van. 1980. Macrostructures. Hillsdale, NJ: LEA.

Grice, P. 1989. Logic and conversation. In P. Grice: Studies in the Way of Words, 22-40. Cambridge, Massachusetts: Harvard University Press.

Johnson-Laird, P.N. 1983. Mental Models. Cambridge: Cambridge University Press.

Lambrecht, K. 1994. Information Structure and Sentence Form. Topic, Focus and the Mental Representations of Discourse Referents. Cambridge: Cambridge University Press.

Naess, A. 1966. Communication and Argument. Oslo: Universitetsforlaget.

Polanyi, L. 1995. The linguistic structure of discourse. CSLI Publication.

Togeby, O. 1993. Praxt. Pragmatisk tekstteori 1-2. Århus: Aarhus Universitetsforlag.

Ulbaek, I. 2001. Pipelines and pipelining: a theoretical discussion of a concept to explain coherence between paragraphs. In L. Degand (ed.), Multidisciplinary Approaches to Discourse, 41-49. Amsterdam: Stichting Neerlandistiek.

Ulbaek, I. 2005. Sproglig tekstanalyse. Introduktion til pragmatisk tekstanalyse. Copenhagen: Academica.

Ulbaek, I. 2013a. Andenordenskohærens. In NyS, 45: 73-103.

Ulbaek, I. 2013b. Har tekstafsnit realitet? In S. Borchmann (ed.), Gode ord er bedre end guld: Festskrift til Henrik Jørgensen i anledning af 60-årsdagen, 501-514. Aarhus: Aarhus Universitetsforlag.

Wadler, J. 2013. The Sex Toys in the Attic. New York Times, November 9. 